\title{
KINERJA PT. BANK SYARIAH XYZ CABANG DEPOK MENGGUNAKAN BALANCED SCORECARD
}

\author{
Budi Rahardjo \\ budi.rahardjo@untidar.ac.id \\ Universitas Tidar \\ Jl. Kapten Suparman No. 39, Potrobangsan, Magelang Utara, Jawa Tengah 56116
}

diterima: 20/12/2019; direvisi: 26/2/2020; disetujui: 27/2/2020

\begin{abstract}
The growth and development of Islamic banking in Indonesia brings an atmosphere of competition in the banking business discourse. PT Bank syariah XYZ is one of the largest sharia banks that always try to provide the best service to their customers in a professional manner. In the midst of fierce competition, PT Bank Syariah XYZ is currently experiencing a setback in performance marked by increasing NPF. The results obtained from performance measurements using the Balanced Scorecard approach to determine the size of the results of each target as a tangible measure, namely the size of the results indicated by an increase in revenue and a decrease in NPF PT Bank Syariah XYZ Depok Branch, customer satisfaction index, increase in the number of accounts, increasing the number of excellent services, efficiency of Teller and CS queues with customers, increasing the number of ATM machines and transaction time efficiency, increasing the quality and competence of employees, reliability of technology and information as well as increasing employee satisfaction and motivation.
\end{abstract}

Keywords: balanced scorecard; islamic bank; company performance; business process; islamic finance

\begin{abstract}
Abstrak
Tumbuh dan berkembangnya perbankan syariah di Indonesia membawa suasana kompetisi dalam wacana bisnis perbankan. PT Bank syariah XYZ merupakan salah satu bank syariah terbesar yang selalu berusaha memberikan pelayanan terbaik kepada nasabahnya secara professional. Ditengah persaingan yang ketat, PT Bank syariah XYZ saat ini mengalami kemunduran kinerja yang ditandai oleh meningkatnya nilai NPF. Hasil yang diperoleh dari pengukuran kinerja menggunakan pendekatan Balanced Scorecard untuk mengetahui ukuran hasil setiap sasaran sebagai ukuran tangible, yaitu ukuran hasil ditunjukkan dengan peningkatan pendapatan dan penurunan NPF PT Bank Syariah XYZ Cabang Depok, indeks kepuasan nasabah, peningkatan jumlah rekening, peningkatan jumlah layanan prima, efisiensi antrian Teller dan CS dengan nasabah, peningkatan jumlah mesin ATM dan Efisiensi waktu transaksi, peningkatan kualitas dan kompetensi karyawan, kehandalan teknologi dan informasi serta peningkatan kepuasan dan motivasi karyawan.
\end{abstract}

Kata Kunci: balanced scorecard; bank syariah; kinerja perusahaan; bisnis proses; keuangan muslim 


\section{PENDAHULUAN}

Tumbuh dan berkembangnya institusi keuangan syariah di Indonesia membawa suasana kompetisi yang ketat dalam wacana bisnis perbankan. Selain kehadiran bank konvensional, masyarakat kini disuguhi pilihan alternatif untuk menginvestasikan dana mereka di perbankan syariah. Perbankan syariah dibentuk dengan dukungan dari otoritas perbankan di Indonesia yaitu Bank Indonesia. Kelahiran sistem perbankan syariah membawa dampak tersendiri bagi dunia usaha di Indonesia. Industri Perbankan merupakan sektor yang paling banyak diatur dan diawasi (Huda, et. al. 2013).

Menurut Srivastav (2013), bank dalam proses bertindak sebagai perantara dihadapkan dengan berbagai jenis risiko keuangan \& non-keuangan. Ditengah persaingan yang ketat, PT Bank Syariah XYZ mengalami kinerja yang menurun berdasarkan nilai NPF (Non Perfoming Financing) yang semakin meningkat melebihi standar NPF yang ditentukan oleh BI (Bank Indonesia) yaitu dibawah 5\%. NPF merupakan salah satu faktor utama dalam melihat kondisi kesehatan perbankan. Tingkat NPF PT. Bank Syariah XYZ dapat dilihat pada Gambar 1.

Selain nilai NPF yang meningkat, pada tahun 2015 juga tercatat tingkat turnover yang mengalami peningkatan dari tahun-tahun sebelumnya. Gambar 2 memperlihatkan tingkat turnover yang terjadi di PT. Bank Syariah XYZ mulai tahun 2012 sampai 2015. Berdasarkan nilai NPF yang terus naik dan tinggkat turnover yang besar, perlu adanya analisis guna mengetahui apa yang terjadi pada kinerja PT. Bank Syariah XYZ. Pengukuran kinerja yang hanya fokus pada finansial secara parsial tidak cukup digunakan untuk mengukur keberhasilan suatu perusahaan. Sedarmayanti (2011) mengungkapkan bahwa Kinerja merupakan terjemahan dari performance yang berarti hasil kerja seorang pekerja, sebuah proses manajemen atau suatu organisasi secara keseluruhan, dimana hasil kerja tersebut harus dapat ditunjukkan buktinya secara konkrit dan dapat diukur (dibandingkan dengan standar yang telah ditentukan).

Lingkungan kompetitif saat ini, ukuran kinerja keuangan tidak memadai namun harus diintegrasikan dengan langkah-langkah nonfinansial dalam sistem pengukuran kinerja yang dirancang dengan baik (Al-Zwyalif 2012). Perlunya pengukuran perspektif nonfinansial agar dapat membantu perusahaan dalam mengetahui dan mengevaluasi kinerjanya secara keseluruhan dan secara integratif. Pengukuran pencapaian kinerja unit bisnis menjadi lebih komprehensif, tidak hanya ditinjau berdasarkan aspek keuangan saja namun juga harus melibatkan berbagai aspek manajemen lain baik internal maupun eksternal. Aspek internal bertujuan mencegah terjadinya konflik kepentingan antar aspek manajemen yang ada di internal organisasi perusahaan sedangkan aspek eksternal diantaranya adalah untuk mengetahui harapan pelanggan.
Salah satu teknik yang dapat digunakan dalam rangka pengukuran kinerja perusahaan adalah dengan menggunakan balanced scorecard. Balanced Scorecard adalah suatu kumpulan tolak ukur kuantitatif yang dipilih secara selektif dari strategi organisasi. Tolak ukur yang dipilih sebagai alat untuk menyampaikan performance driver beserta hasil yang akan dicapai yang akan digunakan sebagai sarana bagi perusahaan untuk mencapai tujuan strategis. Balanced scorecard (BSC) didefinisikan sebagai suatu alat manajemen kinerja yang bisa membantu sebuah organisasi untuk menerjemahkan visi, misi dan strategi kedalam bentuk aksi dengan memanfaatkan sekumpulan indikator finansial dan juga non finansial yang kesemuanya terjalin dalam suatu hubungan sebab-akibat. Abofaied (2017) dan Al-Najjar (2012) berpendapat Pendekatan BSC dapat dikembangkan dan diterapkan untuk mengukur kinerja di sektor perbankan. Penelitian Elkhouly, et. al. (2015) juga mengungkapkan bahwa konseptual kerangka kerja BSC dapat mengukur efektivitas pada risiko perbankan.

Di antara banyak sistem manajemen kinerja, BSC diidentifikasi sebagai salah satu yang memiliki potensi untuk mempengaruhi peningkatan kinerja dan pertumbuhan organisasi (Al-Zwyalif, 2012) Penulis menggunakan metode balance scorecard untuk mengukur kinerja perusahaan secara komprehensif dan strategis yang terdiri dari 4 perspektif yaitu keuangan, proses bisnis, customer dan learning and growth. Tujuan penelitian ini adalah untuk meningkatkan kinerja dalam mempertahankan stabilitas sehingga perusahaan baik saat ini maupun ke depan akan selalu unggul dalam menghadapi persaingan dan mampu menampilkan performa terbaiknya.

\section{METODE}

Penelitian dilakukan di kantor PT. Bank Syariah XYZ Cabang Depok menggunakan data tahun 2012 sampai 2015. Penelitian ini bersifat deskriptif yang bertujuan untuk memberikan gambaran tentang realitas hasil penelitian secara objektif dan jelas. Jenis data adalah primer dan sekunder. Data primer diperoleh langsung dari karyawan PT. Bank Syariah XYZ Cabang Depok, wawancara mendalam terhadap pimpinan dan kuesioner dengan melibatkan seluruh karyawan. Data sekunder diperoleh dari laporan keuangan dan anual report. Variabel pada penelitian ini adalah empat prespektif balanced scorecard yaitu (1) keuangan, (2) pelanggan, (3) proses bisnis internal dan, (4) pertumbuhan dan perkembangan.

\section{HASIL}

Balanced Scorecard (BSC) diciptakan untuk mengatasi kelemahan sistem pengukuran kinerja yang sebelumnya hanya berfokus pada aspek keuangan saja (Haidiputri dan Ratih 2019). Pengukuran dengan 
menggunakan pendekatan Balanced Scorecard (BSC) mengukur aspek keuangan dan non-keuangan. Langkah awal dalam pengukuran kinerja PT Bank Syariah XYZ Cabang Depok dengan menggunakan pendekatan BSC berdasarkan perspektif pelanggan, perspektif proses bisnis internal serta perspektif pembelajaran dan pertumbuhan adalah menetapkan sasaran-sasaran pada setiap perspektif BSC. Al-Hosaini dan Saudah (2015) Balanced Scorecard (BSC) adalah alat yang berguna yang menghubungkan strategi dengan kinerja dengan langkah-langkah panjang tentang bagaimana berbagai tingkat organisasi berkontribusi terhadap keberhasilan secara keseluruhan.

Sasaran merupakan hasil dari terjemahan visi, misi dan tujuan PT Bank Syariah XYZ Cabang Depok. Sasaran-sasaran yang ditetapkan harus relevan dan tingkat pencapaiannya diukur dengan menggunakan ukuran yang harus relevan pula dengan sasaran yang akan dicapai. Penentuan ukuran kinerja dari sasaran yang akan dicapai dapat menggunakan ukuran hasil sebagai lag indicators dan ukuran pendorong/pemicu kerja sebagai lead indicators. Management model yang dapat memberikan dampak besar pada penerapan KPI antara lain adalah balanced scorecard. Banerjee dan Buoti (2012), key performance indicator merupakan ukuran berskala dan kuantitatif yang digunakan untuk mengevaluasi kinerja organisasi dalam tujuan mencapai target organisasi.

Faktor pendorong kinerja diperlukan untuk mengkomunikasikan bagaimana hasil dari pencapaian sasaran perusahaan diperoleh. Faktor pendorong kinerja tanpa ukuran hasil hanya memungkinkan perusahaan mencapai peningkatan operasional jangka pendek. Pada penentuan tolok ukur dalam pengukuran kinerja harus sesuai dengan sasaran-sasaran yang telah dirumuskan pada keempat perspektif BSC sehingga tolok ukur tersebut dapat mengukur sejauh mana sasaran telah dicapai. Langkah berikutnya yaitu menentukan bobot dari masing-masing perspektif BSC dan sasarannya. Menurut Warren (2011), key performance indicator merupakan sebuah pengukuran yang menilai bagaimana sebuah organisasi mengeksekusi visi strategisnya.

\section{PEMBAHASAN}

Sasaran serta ukuran yang dapat mengukur kinerja berdasarkan tingkat pencapaian dari masing-masing sasaran yang ditetapkan oleh PT Bank Syariah XYZ Cabang Depok adalah perspektif keuangan, perspektif pelanggan, perspektif proses bisnis internal, perspektif pembelajaran dan pertumbuhan. Sasaran PT Bank Syariah XYZ Cabang Depok pada perspektif keuangan yaitu peningkatan pendapatan dan penurunan NPF (non performing financing). Perolehan pendapatan (keuntungan) pembiayaan menjadi ukuran hasil pencapaian sasaran strategis peningkatan pendapatan (keuntungan). Ukuran pendorong pada ukuran hasil pertumbuhan pembiayaan adalah peningkatan margin jual beli dan bagi hasil.

Penurunan NPF (non performing financing), dimana NPF ini merupakan pembiayaan kategori macet yang menjadi beban PT Bank Syariah XYZ Cabang Depok yang harus melakukan penyisihan penghapusan aktiva produktif (PPAP). PPAP merupakan cadangan yang dibentuk dengan cara membebani laba rugi tahun berjalan, untuk menampung kerugian yang mungkin timbul sebagai akibat dan tidak diterimanya kembali sebagian atau seluruh aktiva produktif, penyisihan penghapusan aktiva produktif yang dapat diperhitungkan sebagai komponen modal pelengkap adalah maksimum persentase tertentu. Cadangan yang harus dibentuk sebesar persentase tertentu dari debet berdasarkan penggolongan kualitas aktiva produktif sebagaimana ditetapkan dalam peraturan Bank Indonesia.

Sasaran PT Bank Syariah XYZ Cabang Depok pada perspektif pelanggan yaitu Peningkatan kepuasan nasabah, Peningkatan jumlah nasabah, Pendalaman Nasabah Potensial. Ukuran hasil PT Bank Syariah XYZ Cabang Depok dalam mencapai sasaran peningkatan kepuasan nasabah dapat diukur dengan menggunakan indeks kepuasan nasabah khususnya untuk nasabah tabungan. Berdasarkan survei kepuasan nasabah yang dijadikan sebagai ukuran pendorong dari lag indicator indeks kepuasan pelanggan, kita dapat mengetahui seberapa besar peningkatan yang terjadi mengenai kepuasan nasabah terhadap pelayanan dan produk yang disediakan oleh PT Bank Syariah XYZ Cabang Depok sehingga dapat dijadikan sebagai tolak ukur dalam melakukan perbaikan dan perkembangan di masa selanjutnya.

Pada sasaran peningkatan jumlah nasabah baru, penambahan jumlah pembukaan rekening tabungan dan deposito baru dapat menunjukkan pencapaian dari sasaran tersebut. Oleh karena itu, penambahan jumlah pembukaan rekening tabungan dan deposito baru dijadikan sebagai ukuran hasil untuk sasaran peningkatan jumlah nasabah. Pertumbuhan dari jumlah nasabah baru dapat memacu ukuran hasil dari sasaran peningkatan jumlah nasabah dan dapat dijadikan sebagai ukuran pendorong. Peningkatan jumlah nasabah potensial dapat memicu keberhasilan dalam pencapaian ukuran hasil dari jumlah pelayanan prima pada PT Bank Syariah XYZ Cabang Depok. Perspektif pelanggan Balanced Scorecard, manajemen perusahaan harus mengidentifikasi pelanggan dan segmen pasar di mana unit bisnis tersebut akan bersaing dan berbagai ukuran kinerja unit bisnis di dalam segmen sasaran.

Sasaran PT Bank Syariah XYZ Cabang Depok pada perspektif proses bisnis internal adalah Peningkatan Mutu Pelayanan, Efisiensi proses operasi. Balanced Scorecard adalah satu set khusus dari indikator yang sama pentingnya untuk menganalisis dan mengevaluasi operasi dan pengembangan usaha perusahaan (Dudin 
dan Evgenia 2015). Sasaran yang pertama pada perspektif proses bisnis internal yaitu peningkatan mutu pelayanan. Sasaran ini ditetapkan berdasarkan dengan salah satu tujuan meningkatkan kualitas dan kuantitas kegiatan usaha.

Terdapat beberapa aspek yang harus diperhatikan dalam peningkatan kualitas pelayanan yang diberikan kepada nasabah, yaitu meliputi pelayanan non fisik dan fisik. Pelayanan non fisik terkait dengan pelayanan oleh frontliner kepada nasabah. Pelayanan fisik meliputi tersedianya sarana ATM, papan kurs atau papan pengumuman yang berisi tentang besarnya bagi hasil yang akan diperoleh oleh nasabah pada masing-masing produk yang ditawarkan, keramahan dalam menangani telepon dan kebersihan toilet. Ukuran hasil yang dapat mengukur keberhasilan PT Bank Syariah XYZ Cabang Depok dalam mencapai sasaran peningkatan mutu pelayanan antara lain efisiensi antrian yang terjadi selama proses transaksi berlangsung antara teller dengan nasabah atau transaksi antara customer service dengan nasabah. Antrian yang terlalu panjang dapat membuat nasabah kurang puas dengan pelayanan yang diberikan PT Bank Syariah XYZ Cabang Depok.

Peningkatan efisiensi antrian dipengaruhi dari kecepatan dan ketepatan pada saat proses transaksi. Ukuran hasil yang lain dari sasaran peningkatan mutu pelayanan yaitu dengan peningkatan jumlah mesin ATM. Pengadaan mesin ATM dapat mempercepat transaksi yang ingin dilakukan oleh nasabah. Ukuran hasil efisiensi antrian dan peningkatan jumlah mesin ATM dapat dipacu dengan tingkat kecepatan dan ketepatan selama proses transaksi berlangsung baik itu transaksi melalui teller atau customer services maupun transaksi melalui mesin ATM. Peningkatan sarana dan prasarana PT Bank Syariah XYZ Cabang Depok dapat memicu ukuran hasil peningkatan jumlah mesin ATM. Oleh karena itu, peningkatan sarana dan prasarana dijadikan ukuran pendorong dari ukuran hasil peningkatan jumlah mesin ATM. Sasaran yang kedua adalah peningkatan efisiensi proses operasi.

Efisiensi proses operasi yang dilakukan PT Bank Syariah XYZ Cabang Depok diharapkan dapat mempengaruhi tingkat besarnya biaya operasional. Hal ini juga terkait dengan tujuan dari PT Bank Syariah XYZ Cabang Depok itu sendiri yaitu meningkatkan kualitas dan kuantitas kegiatan operasi. Ukuran hasil yang dapat mengukur keberhasilan PT Bank Syariah XYZ Cabang Depok dalam mencapai sasaran efisiensi proses operasi yaitu dengan efisiensi waktu transaksi nasabah dengan teller maupun transaksi nasabah dengan customer service dan ukuran hasil ini dapat dipacu dengan kecepatan dan ketepatan selama transaksi berlangsung. Peningkatan efisiensi waktu transaksi dipicu oleh tingkat kecepatan dan ketepatan selama proses transaksi. Oleh karena itu, kecepatan dan ketepatan selama proses transaksi dapat dijadikan ukuran pendorong dari ukuran hasil efisiensi antrian.
Sasaran PT Bank Syariah XYZ Cabang Depok pada perspektif pembelajaran dan pertumbuhan adalah Peningkatan kualitas dan kompetensi karyawan, Kehandalan teknologi dan informasi, Peningkatan kepuasan dan motivasi karyawan. Ukuran hasil yang dapat mengukur pencapaian sasaran peningkatan kualitas dan kompetensi yang dimiliki karyawan PT Bank Syariah XYZ Cabang Depok yaitu frekuensi pelatihan yang diberikan kepada karyawan dan jumlah partisipasi karyawan yang mengikuti pelatihan. Semakin tinggi frekuensi pelatihan yang diadakan untuk karyawan dan semakin banyak karyawan yang mengikuti pelatihan, maka akan semakin meningkat kompetensi yang dimiliki oleh karyawan. Peningkatan kompetensi karyawan dapat mempengaruhi kualitas pelayanan yang diberikan kepada nasabah terutama bagi karyawan yang menempati posisi frontliner atau posisi yang berhubungan langsung dengan nasabah.

Analisis yang dilakukan terhadap peningkatan kinerja karyawan dapat memicu pencapaian dari ukuran hasil frekuensi pelatihan dan jumlah parisipasi karyawan. Oleh karena itu, analisis peningkatan kinerja karyawan dijadikan ukuran pendorong dari kedua ukuran hasil tersebut. Kehandalan teknologi dan informasi yang dimiliki PT Bank Syariah XYZ Cabang Depok dapat mempermudah perusahaan dalam mendominasi pasar. Bila PT Bank Syariah XYZ Cabang Depok memiliki kehandalan dalam bidang teknologi dan informasi diharapkan dapat mempermudah proses penyampaian pesan dan juga dapat mempermudah pihak internal ataupun pihak eksternal PT Bank Syariah XYZ Cabang Depok dalam memperoleh informasi yang dibutuhkan mengenai kondisi perusahaan dan informasi lainnya yang terkait dengan PT Bank Syariah XYZ Cabang Depok.

Ukuran hasil yang dapat digunakan untuk mengukur pencapaian kehandalan teknologi dan informasi yaitu peningkatan jumlah komputer online dengan sepesifikasi yang baik. PT Bank Syariah XYZ Cabang Depok dalam memperhatikan kepuasan dan motivasi kerja karyawan. Oleh karena itu sasaran yang ketiga yaitu peningkatan kepuasan dan motivasi kerja karyawan. Tingkat kepuasan dan motivasi kerja karyawan sangat mempengaruhi kinerja karyawan dalam bekerja. Kepuasan dan motivasi kerja karyawan yang tinggi akan membuat karyawan bekerja lebih giat dan teliti sehingga dapat memudahkan PT Bank Syariah XYZ Cabang Depok dalam mendominasi pasar.

Tingkat pencapaian sasaran untuk tingkat motivasi dan kepuasan kerja karyawan dapat diukur dengan menggunakan indeks motivasi dan kepuasan kerja karyawan. Menggunakan survei mengenai motivasi dan kepuasan kerja karyawan, maka PT Bank Syariah XYZ Cabang Depok dapat mengetahui seberapa puas dan termotivasinya para karyawan yang dimiliki dalam bekerja. Kepuasan dan motivasi yang tinggi dapat membuat karyawan lebih giat bekerja dan 
menghasilkan output dengan kualitas yang lebih baik. Ukuran pendorong atau lead indicator dari ukuran hasil pada sasaran peningkatan kepuasan dan motivasi yang dimiliki karyawan PT Bank Syariah XYZ Cabang Depok yaitu dengan survei kepuasan dan motivasi karyawan. Pada Tabel 1 dapat dilihat sasaran beserta ukuran BSC PT Bank Syariah XYZ Cabang Depok dengan pendekatan BSC pada tahun 2016. Sejalan dengan penelitian Glaveli dan Karassavidou (2011), yang menyatakan ada bukti dalam literatur manajemen yang mendukung fakta bahwa perspektif pembelajaran dan pertumbuhan dapat mengarah pada hasil keuangan yang lebih baik.

\section{KESIMPULAN}

Penelitian ini menarik kesimpulan yaitu evaluasi kinerja PT Bank Syariah XYZ Cabang Depok dilakukan dengan menentukan ukuran hasil setiap sasaran sebagai ukuran tangible, yaitu ukuran hasil (1) Perspektif keuangan ditunjukkan dengan peningkatan pendapatan dan penurunan NPF (Non Performing Financing) PT Bank Syariah XYZ Cabang Depok; (2) Perspektif pelanggan dipicu oleh ukuran hasil yang terdiri atas indeks kepuasan nasabah, peningkatan jumlah rekening, peningkatan jumlah layanan prima; (3) Perspektif proses bisnis internal efisiensi antrian Teller dan CS dengan nasabah, peningkatan jumlah mesin ATM dan Efisiensi waktu transaksi; (4) Perspektif pembelajaran dan pertumbuhan memiliki ukuran hasil yang terdiri atas peningkatan kualitas dan kompetensi karyawan, kehandalan teknologi dan informasi serta peningkatan kepuasan karyawan.

\section{DAFTAR PUSTAKA}

Abofaied A. 2017. Evaluation of Bank's Performance By Using Balanced Score Card: Practical Study In Libyan Environment. International Journal of Business and Management. 5(1): 1-14. DOI: 10.20472/BM.2017.5.1.001

Al-Najjar S M. dan Khawla H. K. 2012. Designing a Balanced Scorecard to Measure a Bank's Performance: A Case Study. International Journal of Business Administration. 3(4): 44-53

Al-Hosaini F F dan Saudah S. 2015. An Exploration of Inclusion of Spirituality into the Balanced Scorecard (BSC) to Support Financial Performance: A Review. Asian Social Science. 11(9): 289-299

Al-Zwyalif I M. 2012. The Possibility of Implementing Balanced Scorecard in Jordanian Private Universities. International Business Research. 5(11): 113-120. http://dx.doi.org/10.5539/ibr. v5n $11 p 113$

Banerjee J. dan Buoti C. 2012. General specifications of KPIs. International Telecomunnication Union.

Dudin M N dan Evgenia E F. 2015. The Balanced Scorecard as a Basis for Strategic Company Management in the Context of the World Economy Transformation. Asian Social Science. 11(3): 282288. DOI 10.5539/ass.v11n3p282.

Elkhouly S M. Mohamed M I. Mohamed M E F. dan Amal S K. 2015. Measuring the Effectiveness of Banking Risk Balanced Scorecard in Enhancing Bank Value. International Journal of Economics and Finance. 7(6): 139-152. doi:10.5539/ijef.v7n6p139.

Glaveli N. dan Karassavidou E. 2011. Exploring a possible route through which training affects organizational performance: the case of a Greek bank. The International Journal of Human Resource Management. 22(14): 2892-2923. http://dx.doi.or $g / 10.1080 / 09585192.2011 .606113$

Haidiputri T A N. dan Ratih N C. 2019. Penggunaan Metode Balance Scorecard Dalam Pengukuran Kinerja Perusahaan Daerah Air Minum(PDAM) Kota Probolinggo. Jurnal Manajemen Bisnis. 6(2): 59-68

Huda N. Ivo S. dan Efendy Z. 2013. Pengukuran Kinerja Perbankan Syariah Dengan Pendekatan Balance Scorecard. Jurnal Etikonomi. 12 (1): 21-32

Sedarmayanti. 2011. Manajemen Sumber Daya Manusia, Reformasi Birokrasi dan Manajemen Pegawai Negeri Sipil. PT Refika Aditama. Bandung.

Srivastav, S. 2013. A study of enterprise risk Management in banks. Journal of Management-GyanprathaACCMAN. 5(1): 1-10.

Warren, J. 2011. Key performance indicators (KPI) definition and action: Integrating KPIs into your company s strategy. ATI. London. 


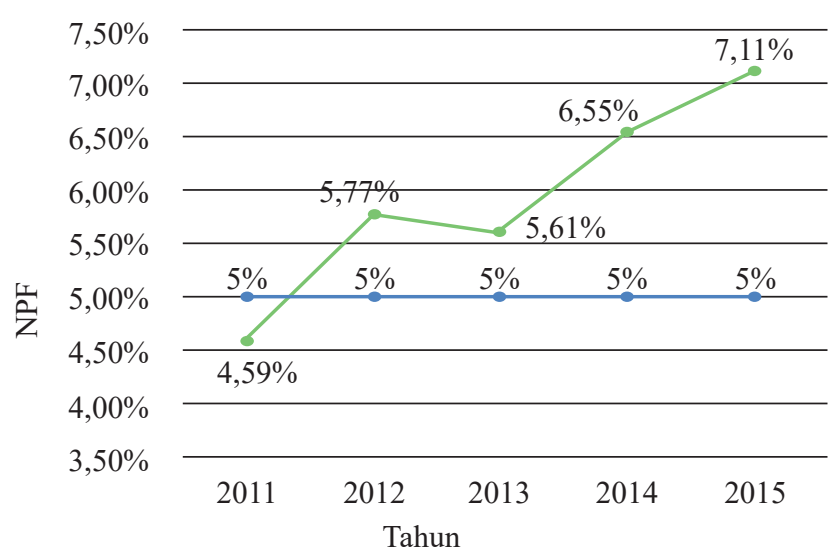

- NPF Bank XYZ — Standar NPF BI

Sumber: Annual Report Bank Syariah XYZ 2015

Gambar 1. Grafik NPF Bank XYZ tahun 2011 - 2015

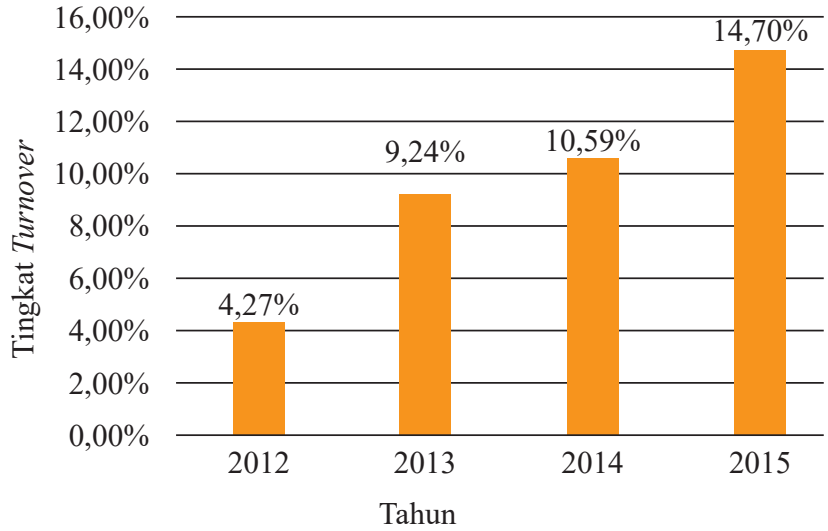

Sumber: Annual Report Bank XYZ 2015

Gambar 2. Tingkat turnover PT. Bank XYZ tahun 2012 - 2015

Tabel 1. Sasaran beserta ukuran BSC PT Bank XYZ Tbk Cabang Depok

\begin{tabular}{lcc}
\hline \multirow{2}{*}{ Sasaran } & Ukuran \\
\cline { 2 - 3 } & Ukuran Hasil (Lag Indicator) & Ukuran Pendorong (Lead Indicator) \\
\hline
\end{tabular}

Perspektif Keuangan

1. Peningkatan pendapatan (keuntungan)

Perolehan pendapatan pembiayaan Penurunan pembiayaan bermasalah
Peningkatan margin jual beli dan bagi hasil Peningkatan ketepatan waktu pembayaran

Perspektif Pelanggan

1. Peningkatan kepuasan nasabah

2. Peningkatan jumlah nasabah

3. Pendalaman Nasabah Potensial
Indeks kepuasan nasabah Pertumbuhan jumlah rekening Jumlah layanan prima
Survei kepuasan nasabah tabungan Peningkatan jumlah nasabah baru Peningkatan nasabah potensial

\section{Perspektif Proses Bisnis Internal \\ 1. Peningkatan Mutu Pelayanan}

2. Efisiensi proses operasi
Efisiensi antrian teller dan customer Kecepatan dan ketepatan proses transaksi service dengan nasabah

Peningkatan jumlah mesin ATM Peningkatan sarana dan prasaranan Efisiensi waktu transaksi teller dan Kecepatan dan ketepatan proses transaksi customer service dengan nasabah

\footnotetext{
Perspektif Pembelajaran dan Pertumbuhan

1. Peningkatan kualitas dan kompetensi karyawan Frekuensi pelatihan

2. Kehandalan teknologi dan informasi Jumlah komputer online

3. Peningkatan kepuasan dan motivasi karyawan Indeks kepuasan karyawan

\author{
Analisis peningkatan kinerja karyawan \\ Peningkatan fasilitas perusahaan
} Survei kepuasan karyawan
} 